\title{
Arte e Psicologia em Vergílio Ferreira
}

\author{
Adriana Freire Nogueira \\ FCHS-CIAC - Universidade do Algarve /CECH-UC
}

\section{Rui Diniz Monteiro}

CIAC - Universidade do Algarve

Resumo: Neste artigo, selecionam-se as reflexões que Vergílio Ferreira vai fazendo sobre a Psicologia sobretudo na sua obra ensaística, com particular enfoque, mas não exclusivamente, no seu primeiro livro de ensaios de 1957, Do Mundo Original. A partir do seu olhar crítico em relação a esta ciência, vai-se procurar revelar como, umas décadas mais tarde, algumas correntes da terapia comportamental, designadas genericamente como de terceira geração, fazem suas aquelas críticas e lhes procuram responder. Finalmente, busca-se também demonstrar que a alternativa à visão psicológica do ser humano, procurando a sua realização, que Vergílio Ferreira apresenta e que passa por uma ideia de vivência da Arte, tem múltiplos pontos de contacto com algumas das terapias comportamentais de terceira geração, nomeadamente com a Terapia de Aceitação e Compromisso e com o Mindfulness.

Palavras-chave: Vergílio Ferreira, Psicologia, Arte, Mindfulness, Terapia de Aceitação e Compromisso

Abstract: In this article, we select the thoughts that Vergílio Ferreira had about Psychology, especially in his essay work, with a particular focus, but not exclusively, in his first book of essays, from 1957, Do Mundo Original. From his critical view on this science, we will try to reveal how, some decades later, the third wave of behavioral and cognitive therapies make similar criticisms and try to respond to these. Finally, we will also try to show the multiple points of contact between some of those therapies, namely with Acceptance and 
Commitment Therapy and Mindfulness based therapies, and the idea of experiencing Art, defended by Vergílio Ferreira as an alternative to the psychological vision of the human being, aiming at his full realization.

Keywords: Vergílio Ferreira, Psychology, Art, Mindfulness, ACT - Acceptance and Commitment Therapy

No seu livro Despenteando Parágrafos. Polémicas Suaves (Quetzal, 2015), Onésimo Teotónio Almeida reúne algumas das polémicas (e ele insiste que sejam chamadas apenas de ideias) que travou com grandes figuras da nossa Literatura, de autores a críticos, de ensaístas a professores.

No entanto, o autor abre uma exceção para Vergílio Ferreira com quem não entra em polémica. Pelo contrário, é perfeitamente claro no elogio rasgado que faz à obra ensaística de Vergílio Ferreira:

(...) Se o ensaísta é um profundo conhecedor de grandes pensadores, está familiarizado com algumas das obras essenciais sobre eles e desenvolveu já uma visão coerente do mundo, natural é que as suas reflexões se revelem dignas do interesse do leitor. 0 ensaio que Vergílio Ferreira preconiza exige aquele tipo de preparação que ele próprio, Eduardo Lourenço e Ortega y Gasset indiscutivelmente possuem. Se a tudo isso acresce a qualidade da escrita que, no caso de Vergílio Ferreira, é a de um dos grandes cultores do nosso vernáculo, então teremos em presença todos os ingredientes necessários para que surja um ensaísta de primeira água. Ler-lhe os ensaios é deslizar com veludosa suavidade sobre uma prosa cristalina de onde as reflexões brotam espontaneamente da palavra, como se leve toque as fizesse abrir em flor. Concordando ou discordando, o leitor deixa-se por ela embrenhar com o autor no labirinto do seu pensamento, viajando pela mão de um estilo seguro e límpido, sentindo, sem dar por isso, que avança porque, no fundo, lhe está a ser transmitido aquilo que, como já vimos, Virginia Woolf exigia do ensaio - prazer. Mesmo que tratem de temas algo deprimentes, por vezes demasiado ensopados na escuridão da vida e do Universo.

Na sua busca do sentido, através de uma escrita obsessiva e sisifística, Vergílio Ferreira conseguiu sempre chegar um pouco mais longe, um tudo nada mais alto, acima de si próprio, como se a aparição que tanto o sustentou e a que tão frequentemente aludia fosse a obra de arte que construiu em palavras. (Almeida 2015: 214) 
É este prazer, bem como este mais longe e mais alto, sempre pela mão de Vergílio Ferreira, referidos aos problemas da existência, que mais fundamentalmente afligem todos aqueles que não se satisfazem com a superficialidade, que se procurará tratar aqui.

A obra de Vergílio Ferreira é particularmente relevante, pois é possível encontrar nela várias facetas. Por um lado, a reflexão filosófica ancorada num profundo humanismo; por outro, a sua inclinação para a linguagem poética (note-se que o seu primeiro interesse na escrita literária foi a poesia, apesar de nunca ter publicado nenhum livro de poemas; mas os rastos vivos desse gosto podem ser encontrados quer no lirismo da sua prosa, quer em alguns poemas que inseriu em Conta-Corrente); por um outro ainda, o seu amor entranhado pela Arte; e, finalmente, o seu trabalho ficcional. Muitas vezes, vemos estas vertentes confluírem simultaneamente no mesmo livro, mas sempre ao serviço da preocupação de encontrar as verdades mais profundas da existência humana.

Neste artigo, o foco incidirá principalmente sobre a sua obra ensaística, particularmente em Do Mundo Original, o seu primeiro livro de ensaios, sobre o qual escreve, no Conta-Corrente 2, em Dezembro de 1978:

Revi as provas de Do Mundo Original. São ensaios meus de há vinte e tantos anos. 0 que neles me envelheceu não são bem as ideias (retomadas muito mais tarde) nem a escrita: o que me fez sentir já fora do lance é uma certa falta de equilíbrio adulto que tem que ver apenas com um certo modo de estar dentro do assunto, uma calma interior no tratá-lo, uma certa densidade ou estabilidade na maneira de lidar com as ideias. Não é bem frieza que se exige, embora ela previna contra os excessos. 0 que se exige é que a emoção, se há razão de a haver, tenha uma qualidade forte que a emoção juvenil nunca tem. (Ferreira 1981b: 233)

Nesta obra (originalmente publicado em 1957), aqueles defeitos alegados por Vergílio Ferreira - a falta de equilíbrio e de calma, a juvenilidade -, são o que, precisamente, permite a revelação de uma intensa emoção, nova e luminosa, a envolver um pensamento sempre ancorado na mais profunda humanidade, mas também igualmente sempre independente, rigoroso e crítico das verdades estabelecidas, como se verá adiante.

Vergílio Ferreira também nunca viu com simpatia a Psicologia como forma 
privilegiada de encarar o ser humano. Neste artigo também se procurará evidenciar o seu olhar crítico e profundamente visionário sobre esta ciência e a sua proposta alternativa de como o Homem deve ser visto e pensado.

\section{A Psicologia e o mecanicismo}

Como disciplina científica, a Psicologia surge oficialmente em 1879, com Wilhelm Wundt. Segundo Schultz \& Schultz (2011), a ciência que se fazia na altura era de caráter profundamente mecanicista, e a Psicologia não escapa a essa influência. Assim, Wundt considerava que, para perceber a mente e o seu funcionamento, havia que estudar os seus elementos constituintes básicos (sensações, emoções e perceções elementares).

Nos finais de 1800, Freud funda a Psicanálise. Mais uma vez, o modelo seguido é o da ciência da época, muito centrada no estudo da energia e da mecânica. Sugere-se que a mente é um mecanismo constituído por partes ou, mais exatamente, por instâncias consciente, pré-consciente e inconsciente; e, mais tarde, Ego, Superego e Id.

Depois, em reação à Psicanálise, surge, nos Estados Unidos, o Behaviorismo. No entanto, o modelo conceptual mecanicista não é abandonado: o estudo do funcionamento do ser humano reduz-se apenas ao que é visível e ao que pode ser medido com perfeita objetividade: estímulo (causa) e comportamento (efeito).

A Psicologia Humanista aparece em reação ao Behaviorismo (recusando a redução do ser humano ao estatuto de animal e de máquina) e à Psicanálise (opondo-se, nomeadamente, às suas tendências determinísticas e ao reduzido papel da consciência na forma como o ser humano se pode modelar a si próprio). Mas o foco continuou a ser o "como" funciona o ser humano.

Mais tarde, reconheceu-se que muito do que era ser-se humano ficava de fora e um novo modelo intercalava o pensamento entre o estímulo e o efeito. Mais uma vez, numa perspetiva assumidamente mecanicista, o modelo cognitivista da mente fundamenta-se na metáfora do computador: o cérebro como hardware e a personalidade como software. Depois, acrescentou-se a emoção (Schultz e Schultz 2011).

Quase todas estas perspetivas, desde as mais psicanalíticas até às mais 
comportamentais, têm em comum um modelo de reflexão sempre mecanicista sobre a mente: por um lado, ela é constituída por componentes com funções específicas; por outro, há causas por detrás dos comportamentos, e estes, por sua vez, têm consequências. Quando há "doença", procuram-se as partes defeituosas do mecanismo (emoções, memórias, esquemas, hábitos, pensamentos, etc., problemáticos), para as eliminar, ou reparar ou, ainda, substituir, a fim de que a "máquina" volte a funcionar normalmente; ou identificamse os "erros" existentes na própria estrutura física do mecanismo para, se tal for possível, proceder a uma reparação (normalmente, por via da farmacopeia).

O mecanicismo tem sido uma das mais bem-sucedidas abordagens científicas da realidade, não surpreendendo a tentação de a estender ao mundo mental do ser humano. Porém, lembremo-nos de que as teorias físicas aplicadas ao macrocosmo se tornam inválidas quando se entra no microcosmo. Suspeita-se, atualmente, que com a passagem da vida real e exterior à vida mental, algo de semelhante se passa: haverá uma mudança de paradigma e as leis não são as mesmas.

Note-se que aquela visão mecanicista não é só partilhada pelos cientistas ou pelos psicólogos clínicos, mas também pelas pessoas comuns. Estas últimas consideram, inclusivamente, que às vezes lhes faltam determinados "componentes", como a autoestima ou a autoconfiança, por exemplo. Ou que transportam consigo componentes defeituosos que precisam de ser removidos, como medos, pensamentos negativos ou memórias traumáticas. E consideram que, sem essa "reparação", não é possível ter uma vida de qualidade. Todas estas crenças são completamente reforçadas pela maior parte das teorias psicoterapêuticas que apareceram até hoje (Harris 2009).

É a este consenso generalizado, tanto da ciência como da cultura popular, que Vergílio Ferreira vai fazer frente, insurgindo-se contra esta visão "psicológica" do ser humano, por a considerar extremamente redutora.

\section{Vergílio Ferreira e a Psicologia}

Em Conta-Corrente 1, Vergílio Ferreira afirma: 
A "psicologia". Não me desagrada ler um livro (romance) em que a análise revela o "como" se é. E todavia, para meu uso, não me interessa. Estes psicólogos esquecem o que está antes (ou depois) da psicologia e é infinitamente mais importante. Que significa o estarmos no mundo? Em que assentar um comportamento? Qual a significação das nossas "ideias" (políticas, etc.)? (...) Antes de saber “como" sou, é-me muito mais perturbador querer saber “o que” sou. E "para quê". (Ferreira 1981a: 27)

Em Aparição (1980), usa a palavra psicologia com um sentido claramente depreciativo:

Mas ofendo-te, velha mulher, aqui a desvendar a tua "psicologia" - eu, que detesto como um insulto essa coscuvilhice das minudências íntimas, esse ofensivo desmontar de relojoaria, como se um ser humano fosse um brinquedo. Mas tu eras alguma coisa mais do que um boneco, eu o sei. Ainda que tu mesma talvez o não soubesses. Porque em ti vivia a fascinação do tempo, o sinal do que nos transcende. (Ferreira 1980: 45)

De um modo mais formal, em Invocação ao Meu Corpo (publicado em 1978, mas escrito em 1966), realça a superficialidade desta disciplina:

Eis porque a psicologia, afectando a profundeza, se nos revela superficial. Falar de um tímido, de um louco, de um colérico, de um modo qualquer de ser raro ou vulgar, é falar das múltiplas formas que uma realidade anterior pode assumir. Ser louco é ser alguém que é louco, ser tímido é ser alguém que se caracteriza pela timidez. (...) A "psicologia" é assim um modo de fixar a exterioridade de um interior, é a forma de determinar o como é aquele que é, é em suma a maneira de surpreender o quem somos, mas só na sua manifestação. Deste modo a "psicologia", sendo do mundo de dentro, é do mundo de fora, inscreve-se no das coisas. 0 sentimento que nos desperta não é assim o espanto mas o da curiosidade. Mundo complexo e infinitesimal, mundo delicado de finíssima estrutura, o mundo da "psicologia" é ainda o da solidez, e a atenção que nos desperta é a que se nos desperta ao sondarmos os segredos da natureza ou um complicado mecanismo de relojoaria. (...) Como numa obra de arte se fala das cores, das linhas, do arranjo das palavras e sons, como se essa obra não fosse o espírito que passa através de tudo isso e isso não fosse apenas a aparência do que nisso se manifesta. (Ferreira 1978: 63)

Repare-se que esta "psicologia" de que Vergílio Ferreira fala não é exatamente a Psicologia, área científica do estudo da mente e do comportamento humanos. Mas, 
tangencialmente, percebe-se que Vergílio Ferreira também não simpatiza com esta - quanto mais não seja, até pela raridade das referências que a ela faz. Aliás, por várias vezes, em Conta-Corrente, verbaliza a aversão que sente relativamente a Freud, apesar de reconhecer a sua importância para os tempos modernos (juntamente com Marx e Nietzsche) (Ferreira 1981a).

Realce-se como, nesta citação, se antecipam crescentes reservas que sistemas de diagnóstico, como o DSM (Diagnostic and Statistical Manual of Mental Disorders) ou o CID (Classificação Internacional de Doenças), levantam a muitos psicólogos na atualidade. (Beutler e Malik 2002)

No entanto, um aspeto curioso da relação que Vergílio Ferreira estabeleceu com a Psicologia surge no seu romance Aparição, de 1959, na voz do Bexiguinha:

- A gente quando fala não pensa nas palavras - dizia -, mas depois tornamos a dizer as mesmas palavras muitas vezes, muitas vezes, e já não são nada, é como que uma fala de doido. (...) - A gente diz por exemplo: «Esta cidade é bonita.» E depois repete: “Esta, esta, esta, esta” assim muitas vezes. E no fim já não é nada, é só som. Mesmo que se repita a frase toda. Primeiro a gente fica com uma ideia na cabeça. Depois já não há nada. (Ferreira 1980: 111)

Ora, em 1928, Edward Bradford Titchener escreve:

Repeat a word over and over again, with sustained attention to the auditory-kinaesthetic complex. The word soon becomes meaningless; the direction of attention has given a sort of hypnotic narrowness to consciousness, the associative context of the word is cut off, and the bare perception remains. (Titchener 1928: 425)

Terá Vergílio Ferreira lido esta obra antes de escrever Aparição, tendo adaptado esta ideia ao que pretendia expressar no seu romance? Talvez nunca o venhamos a saber. Curiosamente, este procedimento volta a ser recuperado hoje em dia pela Terapia da Aceitação e do Compromisso, mas com fins terapêuticos (Hayes et alii 2012: 248). 


\section{“Resposta" das Psicoterapias Comportamentais de 3a Geração a Vergílio Ferreira}

Vergílio Ferreira está, pois, contra a arbitrariedade da psicologia (Ferreira 1986: 351). Observe-se que essa arbitrariedade se revela nas visões psicológicas do Homem, bem como nas correspondentes teorias de intervenção psicológica, que têm surgido ao longo dos últimos 150 anos; e que, após um momento inicial de entusiasmo, têm falhado sistematicamente na compreensão desse mesmo Homem.

Pelo período de 5 a 6 anos, Kazdin (2000) fez um levantamento das psicoterapias disponíveis, só para aplicação a crianças e adolescentes até aos 18 anos e, após um processo de seleção muito rigoroso, chegou às 551. Mesmo assim, refere que muitas psicoterapias existentes e em uso ficaram de fora; e que muitas outras foram entretanto surgindo, enquanto estava a preparar o livro para publicação. (Kasdin 2000: 229). Já Joyce-Moniz (2010) fala em mais de quinhentas psicoterapias em estudo nas universidades. Esta proliferação parece ser indicativa, por um lado, da necessidade que o mundo tem de encontrar uma abordagem satisfatória do ser humano, e, por outro, da falência de todos estes modelos em o definir, em o compreender e em o conseguir ajudar.

Em Conta-Corrente 5 (1987), Vergílio Ferreira acrescenta um outro aspeto:

(...) a "psicologia" é campo aberto à imaginação, à gratuidade, ao charlatanismo (...). (...) o homem é o lugar do arbitrário porque nele cabe tudo. (...) 0 amor, a alegria, a tineta melancólica, o sonho etc. podem ser explicados por aquilo que nos apetecer, podem contar [sic] todas as variantes de explicação ou manifestação etc. (Ferreira 1987: 81)

De facto, um número tão elevado e sempre crescente de muito mais de meio milhar de modelos de psicoterapia só prova que o ser humano pode acreditar em tudo o que a imaginação possa conceber (Joyce-Moniz 2010).

Com a consciência de todos estes problemas, surge, em finais do séc. XX, um grupo de teorias psicoterapêuticas que têm vindo a afirmar-se nestes últimos anos, a que foi dado o nome de "Psicoterapias Comportamentais de $3^{\underline{a}}$ Geração" (em parte ligadas ao 
Behaviorismo Radical que considera e inclui tudo o que se passa na pessoa como sendo comportamento relevante: pensamentos, emoções, sensações, sentimentos, memórias, inclinações/apetites e, claro, os comportamentos propriamente ditos). Procuram promover uma visão mais integradora do ser humano, fazendo confluir nelas as contribuições das teorias psicodinâmicas e psicanalíticas, das teorias sistémicas, das terapias cognitiva e comportamental, da psicologia oriental (o que é uma novidade na Psicologia ocidental), da filosofia e inclusivamente da linguística.

Estas psicoterapias, em particular a Terapia da Aceitação e do Compromisso (ACT Acceptance and Commitement Therapy) e a Terapia Cognitiva Baseada em Atenção Plena (Mindfulness-Based Cognitive Therapy), bem como as teorias que as fundamentam, parecem responder a muitas das objeções apresentadas por Vergílio Ferreira, visto que procuram ter uma visão o mais abrangente possível do ser humano, assim como um objetivo final comum ao que Vergílio Ferreira preconiza: a realização do ser humano através de uma vida plenamente vivida de acordo com o que ele próprio mais valoriza. Aqui, haverá uma aproximação à visão de Vergílio Ferreira, sendo interessante verificar os encontros improváveis que se poderão descobrir entre estas duas perspetivas (sendo que a de Vergílio Ferreira aparece escrita, pela primeira vez, em forma de recolha de ensaios, há 60 anos).

Anote-se, antes de mais, quais as principais linhas de força que orientam os ensaios de Vergílio Ferreira. Primeiro, não são informativos, nem pedagógicos ou didáticos, mas fundamentalmente problematizadores (Ferreira 1977), (Ferreira 1981c). Além disso, para que esta problemática seja abordada de forma especificamente humana, mas sem fazer qualquer concessão a facilitismos de pensamento e de raciocínio, Vergílio Ferreira procura envolver a expressão destes numa emotividade que promova no leitor a fruição também de uma experiência estética (para além da intelectual) (Ferreira 1981c).

Comecemos com a sua primeira coletânea de ensaios, Do Mundo Original, publicado inicialmente em 1957.

Logo na "Abertura", diz Vergílio Ferreira: 
(...) Porque há três zonas no homem: a exterior, que é a da comunicação superficial e quotidiana; a interior, mas que é a do eu-indivíduo, o de "características", o que tem por dimensão a "psicologia"; e a anterior a essa, que é a do eu-pessoa, do eu profundo, do homem, e cuja dimensão é a metafísica. (Ferreira 1979: 12)

A ACT propõe que o eu do ser humano é muito mais amplo e abrangente do que aquilo que cada um de nós pensa. E distingue três sentidos do eu:

- Eu como um Processo Contínuo de Autoconsciência, que corresponde a um conhecimento verbalizado, fluido e contínuo, das experiências que a pessoa vai tendo momento a momento;

- Eu Conceptualizado, que é o objeto de categorizações e avaliações verbais sumárias que a pessoa faz de si;

- Eu Observador, o mais importante, o que está connosco há mais tempo, o único que não é objeto de quaisquer verbalizações, pois não tem conteúdos para serem descritos. É aquele Eu que vê por detrás do olhar que é lançado sobre o mundo, e que sabe que está a olhar, mas que não se sabe a si mesmo, embora sinta essa presença. É o que observa e observou tudo o que há para observar e tudo o que é "coisificável" - os outros Eus, os acontecimentos mentais, bem como todos os eventos do mundo exterior, passados e presentes -, mas que não se pode observar a si mesmo, pois ele é o Observador (Hayes e Smith 2005)

Embora não haja uma coincidência perfeita, atente-se nos paralelismos com a classificação que Vergílio Ferreira apresenta. Propõe-se, além disso, que é a este último sentido do Eu, o Observador, que Vergílio Ferreira se refere quando diz que se trata de "a presença inexorável, iniludível, de uma outra realidade - a que o silêncio conhece" (Ferreira 1979: 13).

Continuando, diz Vergílio Ferreira:

(...) Sei que a vida pode ser reconquistada em plenitude, mas sei igualmente que ela é mentira, se não for recuperada desde a última base. Há decerto uma alegria fácil: ela ignora tristemente a outra, a anterior e única verdadeira. Se é pela consciência que nos valorizamos, se não há "heroísmo" nos brutos - só a partir de uma vivência profunda nós podemos reconhecer-nos inteiros, autênticos, a nós próprios. (Ferreira 1979: 19) 
É esta recuperação da nossa verdade mais profunda e não contaminada que a Mindfulness nos propõe desafiando-nos a prestar «atenção de uma forma especial: de propósito, no momento presente, e sem julgar» (Kabat-Zinn 2003: 24). Vergílio Ferreira dilo por outras palavras e de muitas maneiras, nesta obra. Como por exemplo: "Viver autenticamente é estar presente todo a si próprio, reconhecer-se no mundo como totalização, como espontaneidade" (Ferreira 1979: 21).

É verdade, no entanto, que a Mindfulness é apresentada ao "consumidor" ocidental a uma luz talvez mais funcional e utilitária. Ela surge-nos, então, relativamente modesta no seu objetivo: libertar a mente de hábitos perniciosos para a saúde mental e física do ser humano. No entanto, na sua origem oriental, a Mindfulness sempre foi um caminho para a iluminação espiritual. O Ocidente encontrou nela uma forma útil de autorregulação de emoções e de comportamentos negativos. Mas também reconhece o potencial de crescimento pessoal que a sua prática encerra (Ostafin et alii 2015). E é nesta perspetiva de crescimento que podemos encontrar muitas intersecções com o que Vergílio Ferreira nos diz:

O máximo de uma vida que se cumpre passa pelo máximo de consciência e vivência do momento que lhe coube. E se a um raciocínio é quase sempre fácil opor outro raciocínio que o destrua - são as verdades do sangue, é a sua emoção original que dá ao homem uma presença absoluta no mundo.

(Ferreira 1979: 57)

Porque "Cumprir o nosso destino de homens é vivê-lo profundamente. E o que há de mais profundo no homem é no sangue que se conhece" (Ferreira 1979: 141).

\section{Arte e Psicoterapia}

Independentemente de tudo, Vergílio Ferreira considera que o ser humano é bem mais do que quaisquer explicações mecanicistas que dele queiram dar (isto é, mais do que as explicações que incidem apenas no "como funciona" estritamente observável). No entanto, acredita que esse "mais" pode ser acedido pelas pessoas através da Arte, seja por via da sua fruição, seja principalmente por via da sua criação. Por isso, muitos textos que 
aqui irão ser citados referem-se à arte como a forma mais elevada de o ser humano se realizar como tal, defendendo-se, neste artigo, que é possível aproximar a ideia de Arte em Vergílio Ferreira à ideia de Psicoterapia, considerando ambas como formas privilegiadas de aceder à nossa humanidade mais profunda e mais autêntica.

Pelas próprias palavras de Vergílio Ferreira percebemos como é viável fazer essa aproximação:

A arte exprime; (...) 0 exprimirmos separa-nos, de algum modo, daquilo que exprimimos (que é já de si uma "recordação", que é já, portanto, algo de separado); mas há uma verdade que geralmente se esquece e é que o limite máximo para que tende toda a verdadeira obra de arte é para a anulação dessa distância, dessa separação. (Ferreira 1979: 236)

Tal como na psicoterapia, poder-se-ia acrescentar. Mas essa anulação da distância será feita, agora, a um outro nível.

Vejamos o que a Mindfulness propõe: uma entrega mental total (uma Atenção Plena) a cada momento que está a ser vivido, sem julgamentos, sem raciocínios. Claro que eles vão aparecer, claro que nos distrairemos mais vezes do que desejaríamos. 0 coração da prática da Mindfulness é, então, dar conta da distração e voltar à consciência máxima (que no inglês original é referida, não como consciousness, mas, sim, como awareness). Esta é uma "presença absoluta no mundo" (Ferreira 1979: 141) porque não avalia o que está a fazer faz.

Note-se que a meditação Mindfulness não é uma forma de fugir ou de evitar a vida, como alguns poderão supor. Através desta prática, a pessoa vai acedendo cada vez de forma mais direta àquilo que é mais verdadeiro em si mesma, recuperando-se aí na sua integridade total. Vergílio Ferreira também nos alerta para isto mesmo, atribuindo, no entanto, o nome de Arte a esta vivência ("ela é talvez a melhor forma de uma vivência profunda do instante que passa" Ferreira 1979: 101).

Noutro passo, diz ainda Vergílio Ferreira:

Assim (será preciso dizê-lo?), a verdadeira Arte não é uma "fuga". Fuga é a redução de um homem à 
sua parte transacionável da superfície - esse lado conveniente, disciplinado, onde a voz é só a voz de um ruído exterior de ladrilhos que se agrupam. Que um homem se jogue todo num mínimo gesto seu - e estará certo consigo. Mas então, ele pode ser artista, ele reconhece a Arte, porque à hora derradeira do silêncio, que é a hora da Arte, ele estará tão unido a si próprio como à hora do ruído. Arte não é fuga, mas a demonstração última de uma presença inteira na vida. (Ferreira 1979: 63)

A Mindfulness não é fuga, ou não deve sê-lo, embora possa correr o risco de constituir um refúgio na vida do dia-a-dia, ou seja, uma forma disfarçada de se evitarem experiências vitais que incomodam. Vergílio Ferreira di-lo, ainda em relação à arte: "Em que medida a obra de arte, separando-se embora da vida real, contrapondo-se-lhe até, nos impede, de facto, de comparticipar dessa vida?" (Ferreira 1979: 97).

E responde, mais à frente:

A arte não se separa da vida: retoma-a através de outros sinais, redescobre-a na sua essencialidade. (...) Toda a arte é uma recuperação da vida através do que se lhe julga essencial. 0 seu domínio sobre a realidade restringe-se a uma criação de sinais que não anulam tal realidade, antes a afirmam muitas vezes (e, para o sentir do artista, sempre) com uma força maior. (Ferreira 1979: 98)

Deste modo, Vergílio Ferreira considera que é pela via da Arte que o ser humano se aproxima do absoluto da vida - "só a Arte responde hoje ao infatigável sonho de um Absoluto" (Ferreira 1979: 124) -, enfrentando com toda a sua integridade o desafio que a morte lhe faz, sem a negar: "Assim, o mais profundo sinal humano de uma obra de arte não será decerto a negação do destino, mas a comunicação com as raízes da vida. Vivermos é executarmo-nos até onde o que é da vida perfeita, profunda, viva, se anuncia e nos chama" (Ferreira 1979: 99).

Pode parecer simples, na Mindfulness, "prestar atenção de uma forma especial: de propósito, no momento presente, e sem julgar" (Kabat-Zinn 2003: 24), mas, como avisa Vergílio Ferreira, não o é:

Sou dos que reconhecem agora que a alegria não é fácil, não tanto porque a sua forma imediata, da superfície, não esteja ao nosso alcance, mas por saber que a verdadeira alegria tem raízes profundas e que assim o seu acesso não o pode determinar o que é dos arranjos da superfície. Um sentir não se 
inventa. E tentarmos saber porque somos alegres ou tristes é talvez um pouco vão. As verdades fundamentais fulguram primeiro e depois é que se disciplinam em razões. (Ferreira 1979: 119)

Por isso, a ACT alerta para os múltiplos modos que a linguagem permite que sejamos enganados (Hayes et alii 2012). Por seu lado, a Mindfulness propõe uma abordagem imediata e direta da realidade, sem quaisquer filtros mentais, como vimos. Depois, a tentativa de compreensão do que se conseguiu até pode permitir consolidar aquisições (Yalom 2002), por mais efémeras que elas sejam. Mas, ainda assim, só depois dessa experiência, porque "na vida só vale, é eficiente, tem consequências, o que fala a nossa voz profunda" (Ferreira 1979: 120).

Acrescenta Vergílio Ferreira: "Sentir a vida nos limites extremos da sua revelação é percebê-la de dentro para fora, nos recessos profundos de nós próprios, na fulguração imediata" (Ferreira 1979: 221); ou ainda: “O fundamental, pois, para a perfeita realização do nosso destino de homens, é a profunda união connosco próprios" (Ferreira 1979: 233).

Será, então, credível que possa estar no horizonte da pessoa a realização de uma alegria e de uma plenitude sem reservas? Por outras palavras, poderemos vir a sentir-nos felizes em permanência? Apesar de toda uma indústria da felicidade nos dizer que sim, tal é negado pelos desenvolvimentos mais recentes das investigações psicológicas. Na altura em que estes ensaios foram escritos (anos 50 do séc. XX), parecia haver espaço para uma tal esperança, embora talvez não vinda da psicologia. Refere Vergílio Ferreira: "Imagina-se perfeitamente que um novo período surja amanhã em que o homem, nos seus estritos limites de ser que nasce e morre 'gratuitamente', se reconheça vivendo em plenitude, em alegria" (Ferreira 1979: 120).

Mais à frente, acrescenta lucidamente: "Mas exigir-se-nos isso a nós é decerto excessivo: o limite visível para nós é apenas o da resignação - que não é esquecimento, nem renúncia à ação, mas a aceitação corajosa do estrito reduto que nos pertence" (Ferreira 1979:120).

Exatamente o que a ACT preconiza como escape possível do beco sem saída onde muitas vezes as nossas tentativas de controlo sobre a nossa vida mental nos colocam. Uma 
aceitação do que acontece no nosso interior, que não passa por nenhuma forma de submissão, e que não implica nenhuma forma de paralisação ou de desistência, mas, sim, uma "aceitação corajosa" (Ferreira 1979: 120) do que somos mais profundamente, com o fim de nos libertar para orientar a nossa vida de acordo com os nossos valores mais verdadeiros (Hayes et alii 2012).

Mas, atenção, esta liberdade não se pode ficar pela vida mental. A ACT é uma teoria psicoterapêutica behaviorista/comportamental, que visa uma vida vivida no real, com ações concretas. Vergílio Ferreira alerta-nos para esta questão: “Aliás, da consciência da liberdade ao agir, a distância é enorme. E nos limites da efectividade humana, da realização cabal de uma vivência, só a acção (sob qualquer forma que se encare) tem valor real, decide, enfim, do problema" (Ferreira 1979: 225). Ou seja, não interessa tanto se é real ou não a consciência da minha liberdade; porém, se ela existir, serão apenas os seus efeitos práticos e concretos na minha atuação que, em última análise, vão decidir se eu tenho essa consciência ou não.

E que caminho propõe Vergílio Ferreira? Na verdade, não o da meditação, ou das suas inúmeras variantes que a Psicologia põe atualmente à disposição das pessoas, desde as mais simples visualizações até à auto-hipnose. Vergílio Ferreira propõe a via da Arte,

(...) porque o mundo da arte é o do limiar da vida, o mundo inicial, mundo da aparição, do qual ela é o sinal sensível e o eficaz meio de acesso. Ao instante do milagre as razões ignoram-no - elas vêm já tarde, um pouco como os corvos ao cadáver. Frémito de presença sem margens, a arte fala a voz das origens, recupera ao homem o dom da iniciação, da evidência. (Ferreira 1979: 20)

Refira-se, agora, que esta ideia de que as razões são posteriores à decisão de empreender uma ação é confirmada por estudos neurocientíficos entretanto realizados. Benjamin Libet demonstrou que, quando uma pessoa toma consciência de que decide fazer algo, até cerca de 500 milissegundos antes já o cérebro tomou essa decisão. Ou seja, processos neuronais inconscientes precedem e podem causar atos volitivos que a pessoa sentiu que foram decididos em perfeita consciência. 0 que resta de livre-arbítrio, segundo Libet? A escolha de vetar a decisão e de bloquear o desempenho do ato (Libet 1999). 
Também a isto acrescenta Vergílio Ferreira, na linha da posição de Libet, mas indo talvez bem mais além, sem, no entanto, trair a ideia original:

Mas se a liberdade é impensável, como milenariamente o sabemos, em situação alguma nos furtamos à certeza de que podemos vivê-la. A consciência não é pura passividade. No ato de operar-se, reinventa-se autónoma, centrifugamente, ignora, decerto, até às suas raízes, o que há de centrípeto numa determinação. 0 mais convicto determinista não se exime, suponho, à responsabilidade. (Ferreira 1979: 22)

Ou seja, a pessoa pode não ter culpa do que se vê a fazer. Mas é responsável pelo que pode depois fazer quanto a isso.

E como vai a pessoa exercer essa responsabilidade? Apenas o pode fazer à luz dos valores que escolheu, desde as suas raízes mais profundas, para orientar a sua vida. Onde nascem esses valores, onde se encontram essas raízes? Vergílio Ferreira responde afirmando que "em qualquer ato humano o mais remoto ou mais condicionado está implícita uma escolha original" (Ferreira 1979: 22) E essa escolha vem de que "Uma vida aspira sempre a uma justificação de si própria, a uma finalidade" (Ferreira 1979: 111).

A ACT aborda também esta questão dos valores considerando-a um passo essencial para o ser humano viver integralmente e com plenitude a sua vida (Hayes et alii 2012). Sobre a sua escolha, diz Vergílio Ferreira:

Daí o dizermos que a arte é de algum modo um absoluto. Em face de uma obra de arte, o problema não se põe em termos de sabermos em que medida é ela verdadeira ou falsa (como não discutimos se é "verdade" ou "erro" o mundo real ou uma profunda vivência), mas põe-se, sim, nos termos de verificarmos em que medida aderimos a ela ou não. (Ferreira 1979: 37)

Tal como Vergílio Ferreira salienta, face àquilo que nos aparece como um absoluto não interessa discutir da sua verdade mas, sim, saber do nosso grau de adesão. A ACT propõe-nos exatamente esse critério para a escolha dos valores. Se a um valor nós conseguimos pôr razões e justificações, então não é um verdadeiro valor. Este só "existe" quando já não pudermos responder ao porquê ou ao para quê. "A arte não se 'demonstra'. 
Uma obra de ideias implica uma possível alteração de uma qualquer verdade; uma obra de arte é a verdade. (...) a minha adesão não me deixa margem onde uma 'discussão' possa instalar-se" (Ferreira 1979: 39-40).

Trata-se da escolha inicial e original, que já referimos.

A ACT diz-nos que são os valores que tornam a vida significativa e importante, porque eles vão estar na origem de um fluxo de ações no real que reforçam, pela sua própria natureza (ligada ao que é mais importante para as pessoas), o encontro em harmonia das pessoas consigo mesmas. São também os valores que dão uma forma mais fecunda à vida e que estimulam a sua expansão.

Os valores não têm a qualidade de "coisa", segundo esta terapia, mas mais a de "processo contínuo". Por isso se diferenciam de objetivos, que podem ser alcançados e conseguidos; um valor não. Por exemplo, ter a carta de condução e ser um condutor confiável: o primeiro é um objetivo, o segundo um valor.

Os objetivos são fruto de decisões pensadas, enquanto os valores são o resultado de escolhas, de adesões. Que podem ser feitas com o acompanhamento de razões, mas não por causa de razões - neste último caso estarão os objetivos. 0 valor funciona, em termos aristotélicos, como fim último (pré-racional, que não depende de nenhum outro fim e que, por isso, desejamos por si mesmo) (Hayes et alii 2012).

Os valores são então afirmações acerca dos princípios que queremos que orientem os nossos comportamentos e que trazem motivação à nossa vida; representam as nossas aspirações mais profundas, livremente assumidas, acerca do modo como queremos interagir com o mundo, definindo a qualidade que queremos imprimir à pessoa que desejamos ser e, consequentemente, às nossas ações no dia-a-dia (Harris 2009).

Porém, sejam quais forem os valores escolhidos, um está subjacente a todos, explícita ou implicitamente, nesta época que é a nossa: a liberdade. E é mais uma vez Vergílio Ferreira que nos previne: "Só em liberdade se pode ser artista - repete-nos Hegel. Não apenas em liberdade 'exterior', acentuemos, essa que se traduz pela ausência de uma imposição dos outros, mas ainda em liberdade 'interior', essa que rejeita uma imposição de nós próprios" (Ferreira 1979: 48). 
A ACT e a Mindfulness alertam-nos precisamente para isto: se acreditamos no conteúdo dos nossos pensamentos, se acreditamos que eles nos definem como pessoa, que os limites que eles nos propõem são para serem vividos como tais, então tornamo-nos joguetes e não criadores livres do nosso destino pessoal.

Aliás, definir seja o que for tem a sua margem de inconsequência. Porque realidade alguma se fecha numa definição; e até mesmo uma caracterização exaustiva de seja o que for deixa ainda de fora a própria realidade em si mesma, o próprio objeto, a própria coisa una que se caracteriza. (...) (Ferreira 1979: 220)

Por isso, estas terapias têm uma enorme relutância em fazer diagnósticos para atribuir rótulos, a partir de uma lista claramente marcada pela sua época e, portanto, arbitrariamente construída. Não esqueçamos, por exemplo, que a homossexualidade só foi retirada do Manual de Diagnóstico e Estatística das Perturbações Mentais (DSM) em 1973; da Classificação Internacional de Doenças da OMS (CID) em 1990; e da Classificação Chinesa de Perturbações Mentais em 2001.

É irresistível pensar que a base de onde partem muitos desses pensamentos limitadores e redutores, desses rótulos, será o medo, a propósito do qual escreve Vergílio Ferreira: “0 adversário da paz não é apenas a guerra e a sua ameaça: é o medo sob todas as suas formas. E a expressão mais alta da paz é a possibilidade dada ao homem de se reconhecer inteiro na vida pela exaltação do que mais profundamente o pode dignificar como homem" (Ferreira 1979: 115).

Em que consiste essa vida?

Vivermos é executarmo-nos até onde o que é da vida real, profunda, viva, se anuncia e nos chama. Colaborar com a vida que se cumpre, exaltar-lhe o que é da sua grandeza, reconhecer-lhe a voz das origens, aderir ao que de primeiro, de inicial, nela se anuncia, sentir nela absolutamente, ou seja pela plenitude, os sinais da sua original revelação - esse é o dom da arte. Ser artista é esgotar o instante que nos coube. (Ferreira 1979: 247) 


\section{Bibliografia}

Almeida, Onésimo Teotónio (2015), Despenteando parágrafos. Polémicas suaves. Lisboa, Quetzal Editores.

Beutler, Larry E./ Mary L. Malik (ed.) (2002), Rethinking the DSM: A psychological perspective. Washington, American Psychological Association.

Ferreira, Vergílio (1980), Aparição, Lisboa, Livraria Bertrand.

-- (1981a), Conta-Corrente 1, Lisboa, Livraria Bertrand.

-- (1981b), Conta-corrente 2, Lisboa, Livraria Bertrand.

-- (1986), Conta-Corrente 4, Lisboa, Livraria Bertrand.

-- (1987), Conta-Corrente 5, Lisboa, Livraria Bertrand.

-- (1979), Do mundo original, Lisboa, Livraria Bertrand.

-- (1977), Espaço do invisível - III - Ensaios, Lisboa, Livraria Bertrand.

-- (1978), Invocação ao meu corpo, Lisboa, Livraria Bertrand.

-- (1981c), Vergílio Ferreira - Um escritor apresenta-se, Lisboa, Imprensa Nacional Casa da Moeda.

Harris, Russ, (2009), ACT made simple: an easy-to-read primer on acceptance and commitment therapy, Oakland, New Harbinger Publications.

Hayes, Steven C./ S. Smith (2005), Get out of your mind and into your life: the new acceptance and commitment therapy, Oakland, New Harbinger Publications.

Hayes, Steven C./ K. D. Strosahl/ K. G. Wilson (2012), Acceptance and Commitment Therapy: The Process and Practice of Mindful Change, New York, The Guilford Press.

Joyce-Moniz, Luís (2010), Hipnose, meditação, relaxamento, dramatização. Técnicas de sugestão e autossugestão. Porto, Porto Editora. 
Kabat-Zinn, Jon (2003), Aonde quer que eu vá, Alfragide, Oficina do Livro.

Kasdin, A. E. (2000), Psychotherapy for Children and Adolescents: Directions for Research and Practice, New York, Oxford University Press.

Libet, Benjamin (1999). "How does conscious experience arise? The neural time factor", Brain Research Bulletin, 339-340.

Ostafin, B. D./ M. D. Robinson/B. P. Meyer (2015), Handbook of Mindfulness and SelfRegulation, New York, Springer.

Schultz, Duane P./ Sidney Ellen Schultz (2011), A History of Modern Psychology, Tenth Edition. Belmont, Wadsworth.

Titchener, Edward B. (1928). A Text-Book of Psychology, New York, The Macmillan Company.

Yalom, Irvin D. (2002), The Gift of Therapy. An Open Letter to a New Generation of Therapists and Their Patients, London, Piatkus.

Adriana Freire Nogueira é docente Faculdade de Ciências Humanas e Sociais da Universidade do Algarve (onde se doutorou, em 2001, em Literatura e Cultura Clássicas, com uma tese sobre Tucídides), membro do CIAC - Centro de Investigação em Arte e Comunicação - e do Centro de Estudos Clássicos e Humanísticos da Universidade de Coimbra. Tem desenvolvido investigação em diversas áreas da antiguidade, nomeadamente a tradução e a receção dos antigos nas artes e literatura contemporâneas. É autora de livros de divulgação da cultura clássica para os mais jovens (As "Verdadeiras" Aventuras de Hércules e As Novas Aventuras de Hércules), de traduções de filosofia grega (Platão, Eutidemo, INCM, 1999; Platão, Teeteto, Fundação Calouste Gulbenkian, 4⿳a edição, 2015) e de diversos artigos nos temas das suas investigações. 
Rui Diniz Monteiro é licenciado em Psicologia pela Faculdade de Ciências Humanas e Sociais da Universidade do Algarve. Interessa-se sobre as chamadas Psicoterapias de Terceira Geração, a cujo estudo dedica muito do seu tempo. Além de psicologia, interessa-se por literatura, tendo-se tornado voluntário no programa "Voluntários de Leitura" (criado em 2012 pelo CITI - Universidade Nova de Lisboa). É membro do CIAC - Centro de Investigação em Arte e Comunicação, da Universidade do Algarve. 